\title{
HIGHLY ACTIVE CaO FOR THE TRANSESTERIFICATION TO BIODIESEL PRODUCTION FROM RAPESEED OIL
}

\author{
Ying Tang ${ }^{1 *}$, Gang Chen ${ }^{1}$, Jie Zhang ${ }^{1}$ and Yong $\mathrm{Lu}^{2}$ \\ ${ }^{1}$ College of Chemistry and Chemical Engineering, Xi' an Shiyou University, Xi' an Shannxi, \\ China \\ ${ }^{2}$ Shanghai Key Laboratory of Green Chemistry and Chemical Processes, Department of \\ Chemistry, East China Normal University, Shanghai 200062, China
}

(Received March 25, 2010; revised September 19, 2010)

\begin{abstract}
The catalytic performance of commercial $\mathrm{CaO}$ modified by trimethylchlorosilane (TMCS) for transesterification of rapeseed oil and methanol to biodiesel production was studied. It was found that the fatty acid methyl esters (FAME) yield of the modified $\mathrm{CaO}$ was greatly enhanced from $85.4 \%$ to $94.6 \%$ under $65^{\circ} \mathrm{C}$ with 15:1 molar ratios of methanol/oil by using $5 \mathrm{wt} \%$ catalyst (weight to oil). The possible reason lies on promoting the absorption of grease to modified $\mathrm{CaO}$ surface. Both the characterization of the catalyst and the effects of various factors such as mass ratio of catalyst to oil, reaction temperature and molar ratio of methanol to oil were investigated.
\end{abstract}

KEY WORDS: Biodiesel, Base catalyst, $\mathrm{CaO}$, Modification

\section{INTRODUCTION}

Depletion of fossil reserves increases many initiatives to search for alternate fuel, which have same properties as diesel, to supply or replace such fossil fuel [1,2]. Biodiesel, fatty acid methyl esters of seed oils and fats, has already been found suitable for use as fuel in diesel engine. The conventional method for biodiesel production is transesterification of vegetable oils or animal fats with short-chain alcohols (generally methanol) in the presence of catalysts.

Compared to conventional homogeneous strong base or acid catalysts for transesterification, solid base offers several process advantages including better product purity, elimination of waste water used to clean the catalysts, and the opportunity to operate a continuous process. Because of these advantages, many types of solid bases, such as alkali earth oxides and hydroxides, have been reported in the preparation of biodiesel [3, 4]. Among the different heterogeneous basic catalysts, calcium oxide $(\mathrm{CaO})$ was potential one for its low cost, high basic strength $\left(\mathrm{H}^{-}=26.5\right)$ and low methanol solubility. However, the single contact between reagents and catalysts cause the catalyst less active than sodium hydroxide. Many attempts have been made to promote the activity of the alkali earth oxides by increasing the number of basic sites of the catalyst or enlarging the surface area of the catalysts. Watkins et al. promoted the basicity of $\mathrm{CaO}$ by doping $\mathrm{CaO}$ with lithium [5]. However, they are quite expensive or complicated to prepare, which limited their industrial application. Reddy et al. produced biodiesel using nanocrystalline $\mathrm{CaO}$ under room temperature [6], and the results showed that the first three cycles provided $>99 \%$ conversions, decreasing conversions were obtained in the fourth and fifth cycles, respectively. Recently, the research of accelerating catalytic activity of $\mathrm{CaO}$ for biodiesel production has been aimed at activation of $\mathrm{CaO}$ by pretreatment with methanol [7, 8]. However, the activation mechanism is still controversial.

In this research, we attempt to develop an efficient way for the transesterification between rapeseed oil and methanol by using an activated $\mathrm{CaO}$, which would promote the diffusion of grease, a liquid phase, to the catalyst surface, a solid phase. The activation condition and various reaction conditions for transesterification have also been investigated.

*Corresponding author. E-mail: tangying78@xsyu.edu.cn 


\section{EXPERIMENTAL}

\section{Modification of $\mathrm{CaO}$}

The surface modification procedure was as follows: appropriate amount of commercial $\mathrm{CaO}$ particles were added into trimethylchlorosilane (TMCS) solution in hexane under stirring at room temperature for activation. After $24 \mathrm{~h}$, the mixture was separated and washed with hexane in order to remove the excess TMCS; then, the modified $\mathrm{CaO}$ was obtained after a drying vacuum process.

\section{The procedure for the synthesis of biodiesel}

The catalytic activities for the transesterification of rapeseed oil with methanol were measured by typical procedure: a given amount of modified $\mathrm{CaO}$ and $3 \mathrm{~mL}$ methanol were placed in a three necked round bottomed flask equipped with a reflux condenser and a thermometer. Then, the rapeseed oil was added into the mixture and heated at $65{ }^{\circ} \mathrm{C}$ for a certain time. After reaction finished, the excess methanol was distilled off under vacuum. The products were analyzed by the GC (HP-6890, USA) using inner standard. The yield was defined as a ratio of the weight of fatty acid methyl esters, determined by GC, to the weight of fatty acid methyl esters that the oil used in the reaction, which is given in theory.

\section{Catalyst characterization}

X-ray diffraction patterns were recorded on a D/Max-3C X-ray powder diffractometer (Rigalcu Co., Japan); using a $\mathrm{Cu}-\mathrm{K} \alpha$ source fitted with an Inel CPS 120 hemispherical detector. A FTIR infrared spectrophotometer was used to identify the surface group of the catalyst. SEM photograph was taken by Quanta 200 scanning electron microscope equipped with an energy dispersive spectrometer (Philips-FEI Co., The Netherlands).

\section{RESULTS AND DISCUSSION}

\section{Characterization of the catalyst}

Figure 1 shows the IR spectra of the modified $\mathrm{CaO}$. The spectra display bands at 867 and 1477 $\mathrm{cm}^{-1}$, which would correspond to vibration modes of mono and bidentate carbonates. The asymmetric O-Si stretching vibration modes appear as a broad band between 990 and $1358 \mathrm{~cm}^{-1}$, and the band at $469 \mathrm{~cm}^{-1}$ assigned to the $\mathrm{Si}-\mathrm{O}$ bending mode as suggested by Albuquerque [9], which provided great evidence for the chemical combination of modification regent to $\mathrm{CaO}$ surface. The bands at 1621 and $3460 \mathrm{~cm}^{-1}$ are associated with adsorbed water. The important features of the modified $\mathrm{CaO}$ appear in the $\mathrm{C}-\mathrm{H}$ stretching $\left(2800-3000 \mathrm{~cm}^{-1}\right)$ and $-\mathrm{C}-\mathrm{H}$ (alkane) bending $\left(1440 \mathrm{~cm}^{-1}\right)$. It is also evidenced from the characteristic absorption of $\mathrm{C}=\mathrm{O}$ between 2000 and $1500 \mathrm{~cm}^{-1}$ that the presence of calcium carbonate is formed in the catalyst, as evidenced by the two characteristic broad diffraction lines of $\mathrm{CaO}$ in the diffraction pattern (Figure 2). It indicates that the modified $\mathrm{CaO}$ still has strong basic property because it can adsorb $\mathrm{CO}_{2}$ at room temperature.

Figure 2 shows the XRD pattern of the modified $\mathrm{CaO}$. A series of reflections at 32.1, 37.3 and 53.9 are consistent with X-ray diffractograms of $\mathrm{CaO}$. Minor reflections at 17.9, 28.6, 34.1, 46.9 and 50.7 are attributed to $\mathrm{Ca}(\mathrm{OH})_{2}$ phases, which indicates the hydration of fresh $\mathrm{CaO}$ can not be avoided during the catalyst activation [10]. The peak at 29.2 and 38.9 were assigned to the reflection of $\mathrm{CaCO}_{3}$ due to the expose of fresh $\mathrm{CaO}$ in air. Comparing the main peak area, it 
can be seen that the diffraction peaks corresponding to the $\mathrm{CaO}$ phases of commercial $\mathrm{CaO}$ particles were slightly less intense than those at modified $\mathrm{CaO}$, suggesting well degree of crystallinity over modified sample. No diffraction peak of $\mathrm{CaCl}_{2}$, product of TMCS and $\mathrm{CaO}$, can be found in the sample, which indicates that the formed $\mathrm{CaCl}_{2}$ was amorphous.

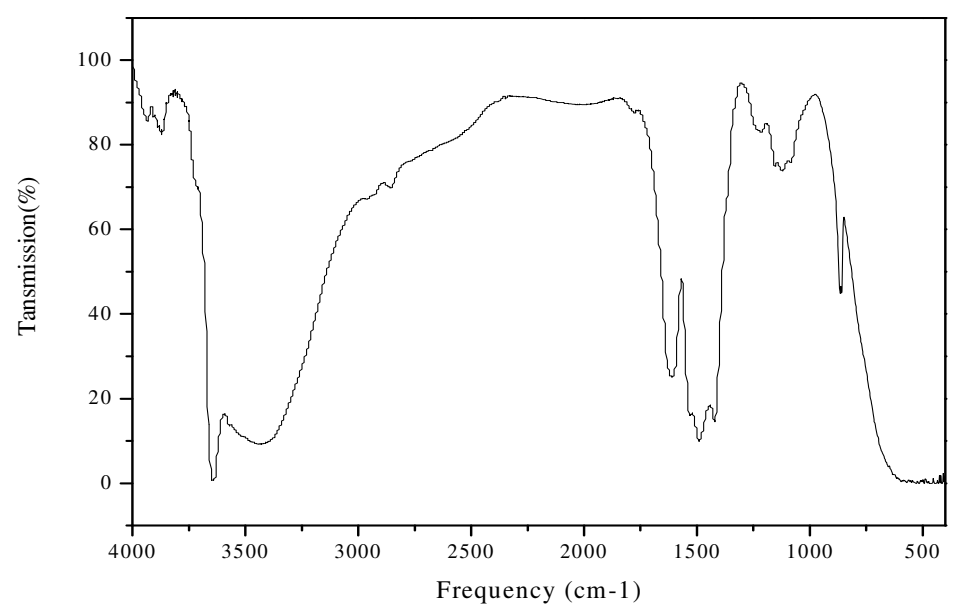

Figure 1. IR pattern of modified $\mathrm{CaO}$.

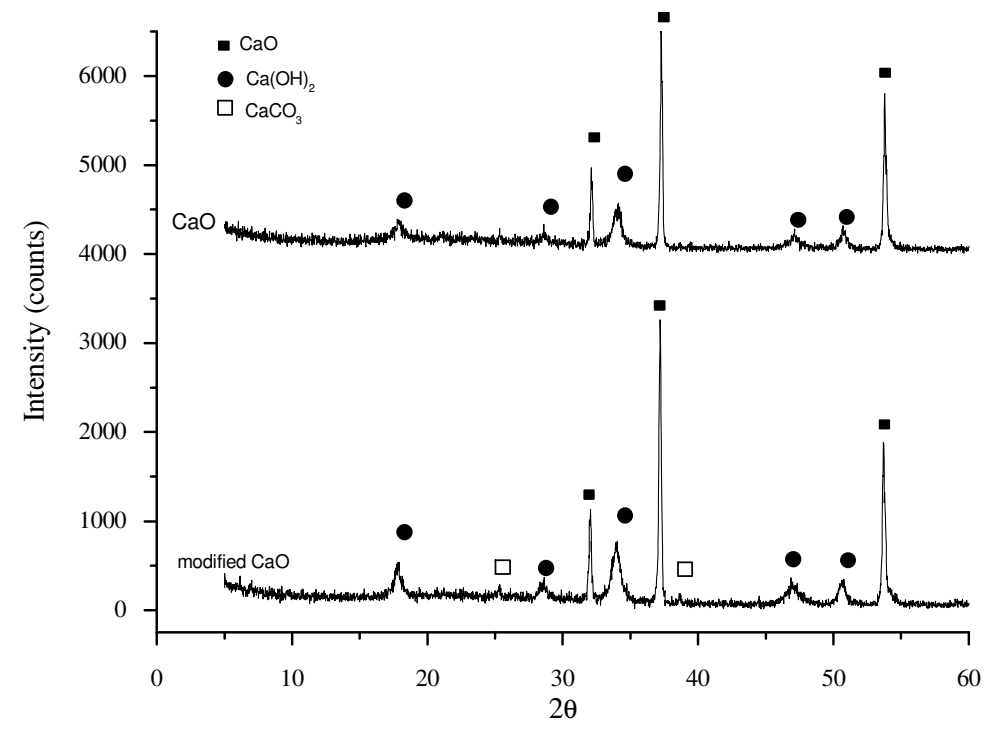

Figure 2. XRD pattern of $\mathrm{CaO}$ and modified $\mathrm{CaO}$.

The SEM micrographs of commercial $\mathrm{CaO}$ particles and modified $\mathrm{CaO}$ sample are shown in Figure 3. Great difference can be found between these two samples. It can be seen that the surface of commercial $\mathrm{CaO}$ particle is built of aggregates, while modified $\mathrm{CaO}$ presents a more exfoliated morphology, which would be associated with its higher catalytic actives. 


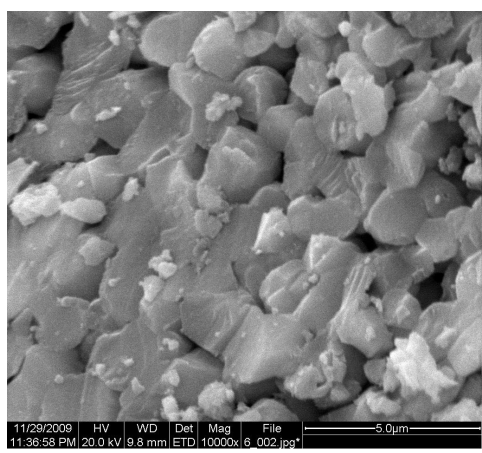

(A)

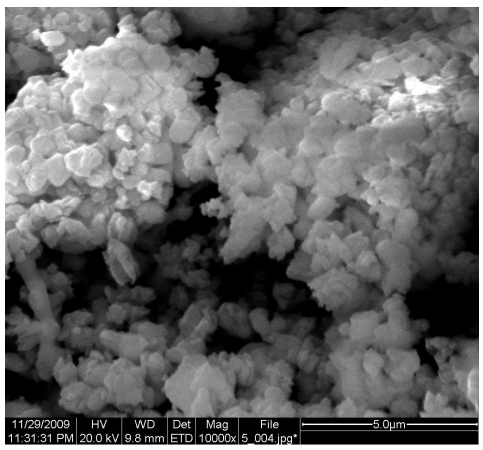

(B)

Figure 3. SEM photo of $\mathrm{CaO}(\mathrm{A})$ and modified $\mathrm{CaO}(\mathrm{B})$.

Catalytic activities test

Influence of amount of modification reagent. To determine the influence of the amount of modification reagent on the activity of the modified $\mathrm{CaO}$ catalyst, the commercial $\mathrm{CaO}$ particles were treated with different amount of TMCS from 0.005 to $2.0 \mathrm{wt} \%$ and then tested for transesterification of rapeseed oil to produce biodiesel. These results (Table 1) indicated that as the amount of TMCS increased, the conversion of triglycerides into FAME also increased. The yield reached an optimal value as the amount of TMCS reached $0.1 \mathrm{wt} \%$, and further increase in amount of TMCS made the catalytic activity decrease. The reason maybe lies on the occupation of active sites on $\mathrm{CaO}$ surface.

Table 1. The influence of amount of TMCS on the reaction.

\begin{tabular}{|l|l|l|}
\hline Entry & The amount of TMCS (\%) & Yield of FAME (\%) \\
\hline 1 & 0.005 & 83.5 \\
2 & 0.01 & 90.7 \\
3 & 0.1 & 94.6 \\
4 & 1.0 & 84.3 \\
5 & 2 & 76.8 \\
\hline
\end{tabular}

The reaction conditions: modified $\mathrm{CaO}$ of $5 \%$ to oil, methanol/oil molar ratio of $15: 1,3 \mathrm{~h}, 65^{\circ} \mathrm{C}$.

Influence of methanol/oil ratio. The alcohol to oil molar ratio is one of the important factors that affect the conversion efficiency of transesterification. The results (Table 2) showed the yield increased with the ratio of methanol to oil is below 15:1. With further increase in the methanol, a very little effect on the FAME yield can be found. This is due to the dilution effect by too much alcohol, and moreover high alcohol amount slow down the separation of the glycerin phase and the methyl ester phase [11]. Therefore, the optimum quantity of methanol was 15:1.

Table 2. The influence of methanol/oil ratio on the reaction.

\begin{tabular}{|l|l|l|}
\hline Entry & Methanol/oil ratio & Yield of FAME (\%) \\
\hline 6 & 3 & 55.3 \\
7 & 5 & 73.2 \\
8 & 10 & 87.6 \\
9 & 15 & 94.6 \\
10 & 20 & 95.2 \\
11 & 30 & 96.1 \\
\hline
\end{tabular}

The reaction conditions: modified $\mathrm{CaO}$ of $5 \%$ to oil, modified $\mathrm{CaO}$ of $5 \%$ to oil, $3 \mathrm{~h}, 65{ }^{\circ} \mathrm{C}$.

Bull. Chem. Soc. Ethiop. 2011, 25(1) 
Influence of reaction time. The yield of methyl esters of transesterification commonly increased with the reaction time. It can be seen from Table 3 that the yields of methyl esters arrived at the maximum value at the reaction time around $3 \mathrm{~h}$ and then slightly decreases at the reaction time of $4 \mathrm{~h}$ and longer. This is because longer reaction caused the hydrolysis of esters and more fatty acids to form soap [12].

Table 3. The influence of reaction time on the reaction.

\begin{tabular}{|l|l|l|}
\hline Entry & Reaction time (h) & Yield of FAME (\%) \\
\hline 12 & 0.5 & 75.1 \\
13 & 1 & 82.3 \\
14 & 3 & 94.6 \\
15 & 4 & 93.4 \\
16 & 5 & 92.8 \\
\hline
\end{tabular}

The reaction conditions: modified $\mathrm{CaO}$ of $5 \%$ to oil, methanol/oil molar ratio of $15: 1,65{ }^{\circ} \mathrm{C}$.

Influence of catalyst concentration. The effect of modified $\mathrm{CaO}$ concentrations on the transesterification was investigated with concentration varying from $1 \mathrm{wt} \%$ to $15 \mathrm{wt} \%$ (weight to oil). The results are summarized in Table 4. Because low concentration of catalyst was insufficient to catalyze the reaction for completion, initially increase in the amount of catalyst resulted in great change of FAME yield. No further enhancement of FAME yield was found when excess catalysts were introduced. The reason for this decreasing trend was due to the formation of soap in presence of high amount of catalysts, which increased the viscosity of the reactants and lowered the yield of ester as suggested by Yang [12]. Therefore the $5 \mathrm{wt} \%$ modified $\mathrm{CaO}$ was optimal in the reactions of this study.

Table 4. The influence of catalyst concentration on the reaction.

\begin{tabular}{|l|l|l|}
\hline Entry & Catalyst concentration (Wt. \%) & Yield of FAME (\%) \\
\hline 17 & 1 & 80.2 \\
18 & 2 & 90.4 \\
19 & 5 & 94.6 \\
20 & 10 & 93.5 \\
21 & 15 & 92.8 \\
\hline
\end{tabular}

The reaction conditions: $3 \mathrm{~h}$, methanol/oil molar ratio of $15: 1,65^{\circ} \mathrm{C}$.

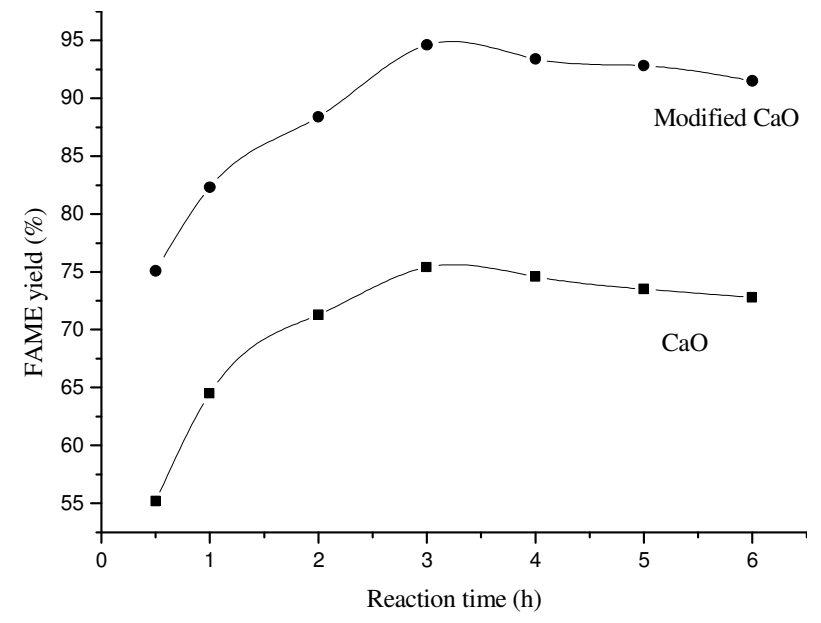

Figure 4. Catalytic activity of modified $\mathrm{CaO}$ and commercial $\mathrm{CaO}$.

Bull. Chem. Soc. Ethiop. 2011, 25(1) 
The comparative study on the modified $\mathrm{CaO}$ and commercial $\mathrm{CaO}$. The comparative study on the catalytic activities of the modified $\mathrm{CaO}$ and commercial $\mathrm{CaO}$ was carried out under the optimum reaction condition obtained from above: $65{ }^{\circ} \mathrm{C}, 15: 1$ molar ratios of methanol/oil, 5 wt. \% catalyst of catalyst (weight to oil). From Figure 4 it can be seen that the yield of FAME over the modified catalyst was enhanced to near to $95 \%$ in the presence of the modified $\mathrm{CaO}$ while $85.4 \%$ for commercial $\mathrm{CaO}$. The possible reason may be contributed to the role of the TMCS, an organic species with many methyls, to promote the diffusion of oil to catalyst surface and enhance the internal diffusion. Therefore, the heterogeneity of the three-phase reaction system will be weak.

\section{CONCLUSIONS}

In this study, an efficient solid basic catalyst for biodiesel production for transesterification of rapeseed oil with methanol was obtained by modification on commercial $\mathrm{CaO}$ particles using trimethylchlorosilane (TMCS). The conversion rate of transesterification reaction rearches to $94.6 \%$ when the reaction is catalyzed by the activated $\mathrm{CaO}$. This is mainly due to the great improvement of diffusion of reagent to modified catalyst surface by similar polarity between surface modified reagent and grease. Furthermore, the change of morphology over modified $\mathrm{CaO}$ to more exfoliate is also related to its high activity. From this view, this novel catalyst has the great potential for particles biodiesel production and other liquid-solid heterogeneous catalytic reactions.

\section{ACKNOWLEDGEMENTS}

This work was financially supported by grants from Scientific Research Foundation for PhD of Xi'an Shiyou University (Z08009), National Science Foundation of China (No. 50874092), Scientific Research Plan Projects of Shaanxi Education Department (08JK414) and the Open Founds of the Shanghai Key Laboratory of Green Chemistry and Chemical Process.

\section{REFERENCES}

1. Fangrui, M.; Milford, A.H. Biores. Technol. 1999, 70, 1.

2. Meher, L.C.; Vidya Sagar, D.; Naik, S.N. Renew. Sustain. Energy Rev. 2006, 10, 248.

3. Kawashima, A.; Matsubara, K.; Honda, K. Biores. Technol. 2008, 99, 3499.

4. Dorado, M.P.; Ballesteros, E.; Lopez, J.F.; Mittelbach, M. Energy Fuels 2004, 18, 77.

5. Watkins, R.S.; Lee, A.F.; Wilson, K. Green Chem. 2004, 6, 335.

6. Reddy Venkat, C.; Oshel, R.; John, G.V. Energy Fuels 2006, 20, 1310.

7. Liu, X.J.; Piao, X.L.; Wang, Y.J.; Zhu, S.L.; He, H.Y. Fuel 2008, 87, 1076.

8. Kawashima, A.; Matsubara, K.; Katsuhisa, H. Biores. Technol. 2009, 100, 696.

9. Albuquerque Mônica, C.G.; Jiménez-Urbistondo, I.; José Santamaría-González. Appl. Catal. A 2008, 334, 35.

10. Granados López, M.; Zafra Poves, M.D.; Martín Alonso, D.R.; Mariscal, F. Cabello Galisteo, R. Moreno-Tost, Santamaría, J.; Fierro, J.L.G. Appl. Catal. B 2007, 73, 317.

11. Yang, F.X.; Su, Y.Q.; Li, X.H.; Zhang, Q.R.; Sun. C. Ind. Crops Products 2009, 29, 622.

12. Eevera, T.; Rajendran, K.; Saradha, S. Renew. Energy 2009, 34, 762. 